\title{
The complexity of natural language mediators and its relation to paired-associate learning'
}

\author{
WILLIAM E. MONTAgUe AND ALEXANDER J. WEARING \\ UNIVERSITY OF ILLINOIS, URBANA
}

\begin{abstract}
Natural language mediators (NLMs) are widely used by Ss in paired-associate learning. Experiments which have documented their effect on learning have largely ignored qualitative differences between them. Two large groups learned different CVC-word lists after which they reported any NLMs they had used. Judges rated the complexity of NLMs using a scale developed by Martin, Boersma, E Cox (1965) with different materials. The results agree with theirs in that complex NLMs produced fewer errors in learning. However, some catezories on the scale were used infrequently which may indicate that, at least with highly meaningful material, a simpler dichotomous categorization (NLM or Rote) may be preferable.
\end{abstract}

A S, in a paired-associate (PA) learning task, tries to integrate pairs into the structure of his language behavior. Underwood \& Schulz (1960), Clark et al (1960) and Bugelski. (1962), among others, all report that Ss use associative devices frequently, even with items low in meaningfulness. Since these devices presumably come from a S's own language experience, we will refer to them as natural language mediators (NLMs). There is some agreement that NLMs are related to facilitation of learning (Jensen \& Rohwer, 1963; Dallett, 1964; Kiess \& Montague, 1965), and are important in retention (Reed, 1918; Groninger, 1966; Montague, Adams, \& Kiess, 1966).

Most experimenters so far have been content to contrast the use of NLMs with rote learning, with little attention given to qualitative differences in NLMs. One exception was an attempt by Martin. Boersma, \& Cox (1965) to evaluate differences in NLM complexity and relate them to PA learning. They had judges examine each associative strategy reported by $S$ and assign it to one of seven categories depending on its complexity, ranging from low, i.e., simple rote or repetition learning, through relations involving physical structure, e.g., letter associations, to high where the items are transformed and integrated into a phrase or a sentence. The purpose of this study was to examine the adequacy of their scaling procedure in predicting errors in PA learning using different materials.

Method

Two unequal groups of undergraduates served as $\mathrm{Ss}$ in the experiment. Each group $(\mathrm{N}=95$ or 70$)$ learned a different 12-item PA list. Stimuli were CVCs of 24-30\% association value (Archer, 1960) and responses were familiar words selected from Thorndike \& Lorge (1944). All Ss learned to a cri- terion of 10 out of 12 correct.

Items were presented automatically on a CRT display in front of each $\mathrm{S}$ for 5 sec. A modified recall procedure developed by Battig (1965) was used. All pairs were presented singly and then each stimulus was presented in a different order to test recall. Items not correctly recalled were presented and tested again. This procedure was repeated until all items were correctly recalled, ending a trial. Then the entire list was presented again and tested to start another trial. Learning ended when $S$ attained criterion on the initial test sequence on a trial. Ss typed their responses on a keyboard directly linked to a computer. All responses were automatically recorded.

Immediately after attaining criterion Ss were asked to respond, in writing, to a questionnaire. Only stimuli were shown on the display, singly, and, on a data sheet $S$ wrote both the response (if he recalled it) and any NLM he used in learning the pair.

\section{Results and Discussion}

Although the association value of the stimuli and the familiarity (frequency, as measured by Thorndike \& Lorge, 1944) of the responses was high and homogeneous, the lists differed in difficulty, i.e., number of errors made to criterion $(p<.05)$. The reason for this difference is obscure.

The data of main importance for this paper are those related to the evaluation of responses obtained on the post-criterion questionnaire. The reports were categorized according to the scheme developed by

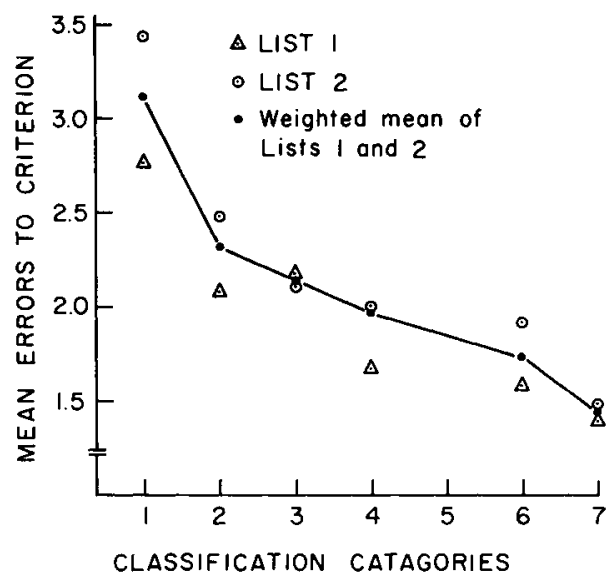

Fig. 1. Mean number of errors per category. 
Table 1. Mean Number of Errors During Acquisition and the Percentage of Responses Falling into Each Category for Roth Lists

\begin{tabular}{|c|c|c|c|c|c|}
\hline \multirow[b]{2}{*}{ Category } & \multirow[b]{2}{*}{ *Description } & \multicolumn{2}{|c|}{ List 1 (Group 1) } & \multicolumn{2}{|c|}{ List 2 (Group 2) } \\
\hline & & $\begin{array}{l}\text { Mean } \\
\text { Errors }\end{array}$ & $\begin{array}{l}\text { Percent } \\
\text { Responses }\end{array}$ & $\begin{array}{c}\text { Mean } \\
\text { Errors }\end{array}$ & $\begin{array}{l}\text { Percent } \\
\text { Responses }\end{array}$ \\
\hline 1 & No Report & 2.77 & 3.7 & 3.44 & 2.8 \\
\hline 2 & $\begin{array}{l}\text { Rote or repe- } \\
\text { tition }\end{array}$ & 2.08 & 33.0 & 2.48 & 32.7 \\
\hline 3 & $\begin{array}{l}\text { Single letter } \\
\text { cues }\end{array}$ & 2.17 & 2.4 & 2.11 & 9.4 \\
\hline 4 & $\begin{array}{l}\text { Multiple letter } \\
\text { cues }\end{array}$ & 1.67 & 0.2 & 2.00 & 3.6 \\
\hline 5 & Word formation & -- & 0.0 & - & 0.0 \\
\hline 6 & Superordinate & 1.58 & 20.2 & 1.92 & 11.4 \\
\hline 7 & Syntactical & 1.40 & 40.5 & 1.48 & 40.1 \\
\hline
\end{tabular}

Martin et al (1965) for each list. Two judges independently assigned each report to a category. The reliability of these ratings was high, i.e., fewer than $3 \%$ were in disagreement. Figure 1 shows the rank order of complexity and the mean number of errors made on pairs falling in each category. In agreement with Martin et al, ease of learning is a function of the complexity of the associative strategy used in learning. The decrease in errors over categories is highly significant, the value of the chi-square obtained from the Errors by Categories contingency table is significant at the $0.1 \%$ level. However, examination of the number of items falling into the various categories questions the advisability or the necessity for using all seven categories in the judging process (see Table 1). Categories 2 (simple rote or repetition learning), 6 and 7 (transformation of items and the use of syntactical relationships) contain $90 \%$ of the 1980 responses recorded. For this material, few reports fall into categories $(3,4$ and 5$)$ which involve NLMs using letter associations or the like. This fact suggests that if S uses a NLM at all, it is a complex one. Therefore, the dichotomous classification system used by Montague et al (i.e., NLM or rote) may offer a simpler means of tabulating the data. The failure to replicate the kind of distribution obtained by Martin et al is probably due to differences in the materials used in the two studies, although their procedure differed somewhat also. They used a recognition rather than a recall procedure on test trials. Martin et al used low association value paralogs for their pairs and, with such materials, it seems likely that physical structure would be used more often in NLM formation than with more meaningful materials such as those used in this study. Boersma, Conklin, \& Carlson (1966) found a similar shift away from these categories when they used meaningful materials. However, although these categories contain few instances, the mean error scores conform to the general expectation of Martin et al that the complexity of the associative strategy is a determinant of PA performance. Therefore, this analysis of the associative stage of learning provides useful information for improving our understanding of learning in PA experiments.

\section{References}

Archer, E. J. A re-evaluation of the meaningfulness of all possible CVC trigrams. Psychol. Monogr., 1960, 74, No. 10 (Whole No. 497).

Battig, W. F. Procedural problems in paired-associate learning research. Psychon. Sci., Monogr. Suppl., 1965, 1, No. 1.

Boersma, F. J., Conklin, R. C., \& Carlson, J. E. Effects of reporting associative strategies on the retention of paired-associates. Psychon. Sci, 1966, 5, 463-464.

Bugelski, B. R. Presentation time, total time, and mediation in paired-associate learning. J. exp. Psychol., 1962, 63, 409-412.

Clark, L. L., Lansford, T. G., \& Dallenbach, K. M. Repetition and associative learning. Amer. J. Psychol., 1960, 73, 22-40.

Dallett, K. M. Implicit mediators in paired-associate learning. $J$. verbal Learn. verbal Behav., 1964, 3, 209-214.

Groninger, L. D. Natural language mediation and covert rehearsal in short term memory. Psychon. Sci., 1966, 5, 135-136.

Jensen, A. R., \& Rohwer, W. D. Jr. Verbal mediation in pairedassociate and serial learning. J. verbal Learn. verbal Behav. $1963,1,346-352$.

Kiess, H. O., \& Montague, W. E. Natural language mediators in paired-associate learning. Psychon. Sci., 1965, 3, 549-550.

Martin, C. J., Boersma, F. J., \& Cox, D. L. A classification of associative strategies in paired-associate learning. Psychon. Sci., 1965, 3, 455-456.

Montague, W. E., Adams, J. A., \& Kiess, H. O. Forgetting and natural language mediation. J. exp. Psychol., 1966, 72, 829-833.

Reed, H. B. Associative aids: I. Their relation to learning, retention and other associations. Psychol. Rev., 1918, 25, 128-155.

Thorndike, E. L., \& Lorge, I. The teacher's word book of 30,000 words. New York: Columbia University Press, 1944.

Underwood, B. J., \& Schulz, R. W. Meaningfulness and verbal learning. New York: Lippincott, 1960.

\section{Note}

1. This research was supported in part by the Joint Services Electronics Program (U. S. Army, U. S. Navy, and U. S. Air Force) under Contract No. DA 28043 AMC 00073 (E); and in part by ONR Nonr-3985(08). 